\title{
COMPETÊNCIAS DO PROFISSIONAL ENFERMEIRO NO CONTEXTO DA ATENÇÃO BÁSICA
}

\section{COMPETENCES OF THE PROFESSIONAL NURSE IN THE CONTEXT OF BASIC ATTENTION}

\author{
Maria Girlane Sousa Albuquerque Brandão, Maria Aline Moreira Ximenes, Lívia Moreira \\ Barros
}

\author{
UNIVERSIDADE ESTADUAL VALE DO ACARAÚ - UVA
}

\begin{abstract}
The objective of this study was to analyze the professional competences of the nurse to provide care in the scope of Primary Care. It is a bibliographical research, of the type integrative review, performed through the databases LILACS, BDENF and MEDLINE, available in the Virtual Health Library, in the time interval from 2011 to 2016. The results showed that there is a consensus regarding to the fact that the nurse has a generalist profile, since besides being able to have coordinating assignments, the nurse must aggregate health care activities, exercising multiple competences, such as: management, nursing consultation, childcare, coordinating community health agents and nursing auxiliaries, permanent education, home visit and nursing preceptor. Thus, the nurse has the challenge of performing a range of activities, aiming at the holistic and qualified nursing care to the patient, becoming essential the acquisition of competencies, seeking to improve the knowledge, skills and attitudes in order to improve their process of job.
\end{abstract}

Key words: Professional Competence. Nursing. Basic Attention.

\section{Resumo}

O objetivo deste estudo foi analisar as competências profissionais do enfermeiro para a prestação de cuidados no âmbito da Atenção Básica. Trata - se de uma pesquisa bibliográfica, do tipo revisão integrativa, realizada por meio das bases de dados LILACS, BDENF e MEDLINE, disponíveis na Biblioteca Virtual em Saúde, no intervalo temporal de 2011 a 2016. Os resultados mostraram que existe um consenso em relação ao fato de que o enfermeiro tem perfil generalista, pois além de poder ter atribuições de coordenação, o enfermeiro deve agregar as atividades de assistência à saúde, exercendo múltiplas competências, como: gestão, consulta de enfermagem, puericultura, coordenar os agentes comunitários de saúde e auxiliares de enfermagem, educação permanente, visita domiciliar e preceptoria de enfermagem. Assim, $o$ enfermeiro tem o desafio de desempenhar uma gama de atividades, visando à assistência holística e qualificada de enfermagem ao paciente, tornando-se essencial a aquisição de competências, buscando aperfeiçoar os conhecimentos, habilidades $e$ atitudes a fim de aprimorar o seu processo de trabalho.

Palavras chave: Competência Profissional. Enfermagem. Atenção Básica. 
Introdução

A Política Nacional de Atenção Básica foi aprovada pela Portaria no 2.488, de 21 de outubro de 2011, estabelecendo a revisão de diretrizes e normas para a organização da atenção básica ${ }^{1}$.

A Atenção Básica $(A B)$ caracteriza-se por um conjunto de ações de saúde, no âmbito individual e coletivo, que abrange a promoção e a proteção da saúde, a prevenção de agravos, o diagnóstico, o tratamento, a reabilitação e a manutenção da saúde. É o contato preferencial dos usuários com os sistemas de saúde. Orienta-se pelos princípios da universalidade, da acessibilidade e da coordenação do cuidado, do vínculo e continuidade, da integralidade, da responsabilização, da humanização, da equidade e da participação social ${ }^{2}$.

Nesse sentido, a atenção básica contribui com o funcionamento das Redes de Atenção à Saúde (RAS) que constituem-se em arranjos organizativos formados por ações e serviços de saúde com diferentes configurações tecnológicas e missões assistenciais, articulados de forma complementar e com base territorial. Tem como princípios: a estruturação da atenção básica como primeiro ponto de atenção e principal porta de entrada do sistema, constituída de equipe multidisciplinar que cobre toda a população, integrando, coordenando o cuidado e atendendo às suas necessidades de saúde ${ }^{1}$.

Assim, o enfermeiro tem na prática desenvolvida em unidades básicas de saúde (UBS) o desafio de implementar o cuidado em enfermagem na construção de relações interpessoais de diálogo, escuta, humanização e respeito. Esta prática perpassa, portanto, pela compreensão do enfermeiro sobre o significado do seu fazer profissional, ou seja, do praticar o cuidado de enfermagem na atenção básica em saúde ${ }^{3}$.

A possibilidade de se traçar competências para a prática do enfermeiro na Atenção Básica é um recurso importante para subsidiar a formação deste profissional. A adoção do modelo de competências, para pensar a formação e atuação do profissional de saúde, possibilita adequar a gênese dos trabalhadores às novas exigências do sistema produtivo, fortalecendo a integralidade do cuidado em saúde, no que tange a Atenção Básica ${ }^{4}$.

O cuidado é considerado como o objeto e a essência da enfermagem, pois essa profissão envolve vários saberes, entre eles, o saber afetivo - a arte de cuidar. Sabendo que o processo de cuidar relaciona-se com atos diferenciados, as competências realizadas pelo enfermeiro se caracterizam como cuidado no momento em que ocorre o respeito, a gentileza, a atenção, a solidariedade e o interesse ${ }^{3}$.

A competência vai além da qualificação do potencial de ação: trata-se de uma mobilização real e produtiva de um conjunto de saberes de natureza diferenciada, formada por cinco componentes, a saber: intelectual; técnicofuncional; comportamental ou pessoal; ética ou política, cujo resultado é reconhecido e valorizado tanto pelo próprio indivíduo como por terceiros ${ }^{5}$.

É de suma relevância delinear as competências do enfermeiro, para que assim, esse profissional tenha um maior entendimento de suas funções, buscando melhorar sua atuação, aperfeiçoando o atendimento à população, de modo a efetivar os princípios do SUS, fortalecimento a enfermagem e a atenção básica ${ }^{6}$.

Assim, objetiva-se analisar as competências profissionais do enfermeiro exigidas para a prestação de cuidados no âmbito da Atenção Básica na literatura científica.

\section{Metodologia}

Trata- se de uma pesquisa bibliográfica, do tipo revisão integrativa que implica em uma ampla análise da literatura, caracterizada como um método de pesquisa que utiliza a prática baseada em evidências. Assim, tem sido considerada um instrumento indispensável no campo da saúde, pois sintetiza as pesquisas disponíveis de um assunto em questão e permite o direcionamento da prática fundamentando-se em conhecimento científico ${ }^{7}$.

Para realização deste estudo foram utilizadas todas as etapas previstas da revisão integrativa: identificação da temática e elaboração da pergunta norteadora, busca em base de dados e estabelecimento dos critérios de inclusão e exclusão, coleta dos dados e definição das informações dos estudos selecionados acompanhadas da categorização, avaliação dos estudos, interpretação dos estudos sendo expressos em resultados e discussão, e por fim, síntese e apresentação do conhecimento.

A pergunta norteadora foi: "Quais as competências profissionais do enfermeiro exigidas na prática de cuidados no âmbito da Atenção Básica?”.

Para alcançar o objetivo proposto, foi realizado um levantamento bibliográfico retrospectivo de artigos de pesquisas completos, na língua portuguesa, no intervalo temporal de 
2011 a 2016, por meio das bases de dados Literatura Latino-Americana e do Caribe em Ciências da Saúde (LILACS), Base de Dados de Enfermagem (BDENF-Enfermagem), Sistema Online de Busca e Análise de Literatura Médica (MEDLINE), disponíveis na Biblioteca Virtual em Saúde (BVS), utilizando os descritores: Atenção Básica and Competências and Enfermagem.

A escolha desta data se justifica pela aprovação da Portaria no 2.488, de 21 de outubro de 2011 que consentiu a Política Nacional de Atenção Básica, estabelecendo a revisão de diretrizes e normas para a organização da atenção básica.

Foram identificados 141 artigos, sendo selecionados 12 artigos para o estudo. Os critérios utilizados para a seleção foram: artigos publicados no intervalo de tempo entre 2011 e 2016; em português; disponíveis online na íntegra; apresentando em sua discussão considerações sobre competências profissionais do enfermeiro no âmbito da Atenção Básica. Os critérios de exclusão foram: artigos repetidos, sendo mantida apenas a primeira versão identificada e artigos que não apresentavam em sua discussão considerações sobre competências profissionais do enfermeiro.

Após a identificação, realizou-se a seleção dos estudos primários, de acordo com a questão norteadora e os critérios de inclusão e exclusão previamente definidos. Todos os estudos identificados por meio da estratégia de busca foram inicialmente avaliados por meio da análise dos títulos e resumos, seguindo com a leitura na íntegra da publicação.

Partindo da seleção das bases de dados, critérios de inclusão, exclusão e leitura completa dos artigos, elaborou-se um quadro sinóptico com o delineamento dos passos metodológicos dessa revisão integrativa (Quadro1).

Quadro 1. Quadro sinóptico com o delineamento dos passos metodológicos

1a Fase: Elaboração da pergunta norteadora
“Quais as competências profissionais do enfermeiro exigidas na prática de
cuidados no âmbito da Atenção Básica?

\section{Resultados e discussão}

Dentre os 14 artigos incluídos na revisão integrativa, observou-se que oito artigos estavam publicados na LILACS e seis artigos na BDENFEnfermagem. Para melhor expressão dos dados dos artigos, foi elaborado instrumento (Quadro
2), que contém os seguintes itens: título (ano), objetivo, tipo de estudo/amostra e principais resultados dos artigos analisados e o (Quadro 3), com a síntese das competências identificadas, implicação para a prática da enfermagem e os artigos que abordam cada competência. 
Quadro 2. Artigos levantados nas bases de dados LILACS e BDENF sobre as competências do profissional enfermeiro no contexto da atenção básica.

\begin{tabular}{|c|c|c|c|}
\hline Título (Ano) & Objetivo & Tipo De Estudo / Amostra & Principais Resultados \\
\hline $\begin{array}{l}\text { 1.Cultivo do bem } \\
\text { viver das pessoas } \\
\text { idosas e tecnologia } \\
\text { cuidativo- } \\
\text { educacional de } \\
\text { enfermagem. (2016) }\end{array}$ & $\begin{array}{l}\text { Realizar avaliação } \\
\text { diagnóstica de } \\
\text { condições de vida e } \\
\text { saúde dos idosos de } \\
\text { uma Unidade Básica de } \\
\text { Saúde. }\end{array}$ & $\begin{array}{l}\text { Pesquisa convergente- } \\
\text { assistencial, com } 13 \\
\text { idosos, que se } \\
\text { desenvolveu em sete } \\
\text { encontros, }\end{array}$ & $\begin{array}{l}\text { O estudo revelou que o } \\
\text { enfermeiro ser facilitador no } \\
\text { desenvolvimento } \\
\text { autocuidado e estimulador dos } \\
\text { idosos para que sejam } \\
\text { protagonistas do próprio } \\
\text { envelhecimento. }\end{array}$ \\
\hline $\begin{array}{l}\text { 2. Consultas de } \\
\text { enfermagem aos } \\
\text { idosos em } \\
\text { assistência básica no } \\
\text { intercâmbio } \\
\text { estudantil } \\
\text { internacional: relato } \\
\text { de experiência } \\
\text { (2016) }\end{array}$ & $\begin{array}{c}\text { Descrever a } \\
\text { experiência discente } \\
\text { sobre as consultas de } \\
\text { enfermagem à } \\
\text { população idosa. }\end{array}$ & $\begin{array}{c}\text { Relato de experiência. } \\
\text { Envolveu } 200 \text { consultas de } \\
\text { Enfermagem e } 117 \\
\text { pacientes participantes } \\
\text { com idade predominante } \\
\text { entre } 65 \text { e } 69 \text { anos } \\
\text { portadores de doenças } \\
\text { crônicas. }\end{array}$ & $\begin{array}{l}\text { A relação de ajuda bem } \\
\text { aplicada proporciona aos } \\
\text { cuidados uma eficácia e uma } \\
\text { qualidade humana que lhe } \\
\text { confere ao mesmo tempo um } \\
\text { caráter de profissionalismo e } \\
\text { uma melhor visibilidade das } \\
\text { ações do enfermeiro. }\end{array}$ \\
\hline $\begin{array}{l}\text { 3. Experiência de } \\
\text { enfermeiros com } \\
\text { computadores na } \\
\text { atenção primária: } \\
\text { Estudo exploratório } \\
\text { (2016) }\end{array}$ & $\begin{array}{l}\text { Identificar a } \\
\text { experiência de } \\
\text { enfermeiros com } \\
\text { computadores na } \\
\text { atenção primária. }\end{array}$ & $\begin{array}{l}\text { Pesquisa exploratória do } \\
\text { tipo Survey de abordagem } \\
\text { quantitativa, desenvolvida } \\
\text { com } 152 \text { enfermeiros. }\end{array}$ & $\begin{array}{l}\text { O computador está presente no } \\
\text { processo de trabalho de } \\
\text { enfermagem, sendo necessária } \\
\text { a utilização efetiva das } \\
\text { tecnologias da informação e } \\
\text { comunicação nos serviços de } \\
\text { saúde e de enfermagem na } \\
\text { atenção primária. }\end{array}$ \\
\hline $\begin{array}{l}\text { 4. Competências do } \\
\text { enfermeiro para o } \\
\text { cuidado paliativo na } \\
\frac{\text { atenção domiciliar }}{\text { (2014) }}\end{array}$ & $\begin{array}{c}\text { Identificar } \\
\text { competências do } \\
\text { enfermeiro para o } \\
\text { cuidado paliativo na } \\
\text { atenção domiciliar }\end{array}$ & $\begin{array}{l}\text { Estudo exploratório com } \\
20 \text { enfermeiros } \\
\text { atuam na atenção } \\
\text { domiciliar para com } 43 \\
\text { competências elencadas } \\
\text { em um questionário. }\end{array}$ & $\begin{array}{l}\text { O consenso favorável às } \\
\text { competências propostas indica } \\
\text { o reconhecimento do } \\
\text { cuidado paliativo como prática } \\
\text { assistencial de enfermagem na } \\
\text { atenção domiciliar. }\end{array}$ \\
\hline $\begin{array}{l}\text { 5. As competências } \\
\text { técnicas dos } \\
\text { enfermeiros na } \\
\text { assistência ao } \\
\text { recém-nascido } \\
\text { (2013) }\end{array}$ & $\begin{array}{l}\text { Analisar os } \\
\text { conhecimentos e } \\
\text { habilidades essenciais } \\
\text { dos enfermeiros que } \\
\text { atuam no atendimento } \\
\text { ao recém-nascido. }\end{array}$ & $\begin{array}{l}\text { Estudo quantitativo, } \\
\text { transversal, descritivo, } \\
\text { realizado com } 12 \\
\text { enfermeiros. }\end{array}$ & $\begin{array}{l}\text { A competência profissional da } \\
\text { enfermeira neonatal se traduz, } \\
\text { então, pela capacidade de } \\
\text { utilizar conhecimentos e } \\
\text { habilidades adquiridos na } \\
\text { prática para a assistência ao } \\
\text { recém-nascido. }\end{array}$ \\
\hline $\begin{array}{l}\text { 6. O desenvolvi- } \\
\text { mento de } \\
\text { competências para a } \\
\text { preceptoria de } \\
\text { enfermagem no } \\
\text { ambiente de atenção } \\
\text { primária à saúde } \\
\text { (2013) } \\
\end{array}$ & $\begin{array}{l}\text { Descrever as atividades } \\
\text { dos preceptores de } \\
\text { enfermagem no } \\
\text { ambiente de atenção } \\
\text { primária e seu papel no } \\
\text { treinamento de } \\
\text { estudantes de } \\
\text { enfermagem. }\end{array}$ & $\begin{array}{c}\text { Estudo descritivo- } \\
\text { exploratório usando uma } \\
\text { abordagem qualitativa, } \\
\text { com onze profissionais de } \\
\text { enfermagem. }\end{array}$ & $\begin{array}{l}\text { O preceptor de enfermagem } \\
\text { deve ter habilidades para } \\
\text { transmitir o conhecimento, } \\
\text { ensinar técnicas, mostrar a } \\
\text { rotina diária aos estudantes de } \\
\text { enfermagem e complementar o } \\
\text { programa de enfermagem. }\end{array}$ \\
\hline $\begin{array}{l}\text { 7. Cuidado à } \\
\text { gestante na atenção } \\
\text { básica: relato de } \\
\text { atividades em } \\
\text { estágio curricular } \\
\text { (2013) }\end{array}$ & $\begin{array}{c}\text { Relatar uma } \\
\text { experiência acadêmica } \\
\text { durante a realização do } \\
\text { EI, da graduação em } \\
\text { Enfermagem. }\end{array}$ & $\begin{array}{l}\text { Relato de experiência } \\
\text { qualitativo com } \\
\text { Profissionais e gestantes } \\
\text { de uma UBS. }\end{array}$ & $\begin{array}{l}\text { O enfermeiro deve ter } \\
\text { competência no manejo das } \\
\text { intercorrências gestacionais } \\
\text { mais comuns, como a anemia, } \\
\text { intercorrências urinárias, } \\
\text { gástricas e acompanhar a } \\
\text { gestante em todo o ciclo } \\
\text { gravídico-puerperal. }\end{array}$ \\
\hline
\end{tabular}

Continua... 
continuação...

\begin{tabular}{|c|c|c|c|}
\hline $\begin{array}{l}\text { 8. Relações de } \\
\text { cuidado entre } \\
\text { enfermeiros da } \\
\text { atenção básica e } \\
\text { cuidadores } \\
\text { familiares de } \\
\text { pessoas com câncer } \\
\text { (2013) }\end{array}$ & $\begin{array}{c}\text { Conhecer as relações } \\
\text { de cuidado entre } \\
\text { enfermeiros e Família e } \\
\text { cuidadores familiares } \\
\text { de pessoas com câncer } \\
\text { do Paraná. }\end{array}$ & $\begin{array}{l}\text { Estudo exploratório- } \\
\text { descritivo, qualitativo de } \\
2011 \text { nos domicílios dos } \\
\text { sujeitos e nas Unidades } \\
\text { Básicas de Saúde. }\end{array}$ & $\begin{array}{l}\text { Compete ao enfermeiro prestar } \\
\text { a assistência humanizada ao } \\
\text { doente e sua família. Cabe } \\
\text { ainda ao enfermeiro coordenar } \\
\text { sua equipe para assistir às } \\
\text { necessidades destes seres em } \\
\text { seus domicílios. }\end{array}$ \\
\hline $\begin{array}{l}\text { 9. Ações do pré-natal } \\
\text { realizadas pela } \\
\text { equipe de } \\
\text { enfermagem na } \\
\text { atenção primária à } \\
\text { saúde, Cuiabá (2013) }\end{array}$ & $\begin{array}{l}\text { Descrever as ações } \\
\text { realizadas pela equipe } \\
\text { de enfermagem na } \\
\text { atenção pré-natal no } \\
\text { município de Cuiabá, } \\
\text { MT. }\end{array}$ & $\begin{array}{l}\text { Estudo descritivo em que } \\
\text { participaram } 182 \\
\text { profissionais da equipe de } \\
\text { enfermagem, atuantes na } \\
\text { Atenção Primária à Saúde } \\
\text { de Cuiabá. }\end{array}$ & $\begin{array}{l}\text { A competência do enfermeiro é } \\
\text { essencial para um pré-natal } \\
\text { qualificado. Onde o mesmo } \\
\text { tem a função de guiar a } \\
\text { gestante por todo o ciclo } \\
\text { gravídico, } \\
\text { informações e realizando o } \\
\text { exame físico nas consultas de } \\
\text { enfermagem. }\end{array}$ \\
\hline $\begin{array}{l}\text { 10. Preceptoria de } \\
\text { enfermagem na } \\
\text { atenção básica: } \\
\text { questão de } \\
\text { competências: } \\
\text { estudo exploratório } \\
\text { descritivo (2012) }\end{array}$ & $\begin{array}{c}\text { Identificar as } \\
\text { competências que o } \\
\text { preceptor necessita } \\
\text { para desenvolver e } \\
\text { para atuar } \\
\text { efetivamente. }\end{array}$ & $\begin{array}{c}\text { Pesquisa qualitativa, } \\
\text { exploratória e descritiva, } \\
\text { realizada } 15 \text { enfermeiros } \\
\text { que exercem preceptoria } \\
\text { em uma unidade básica de } \\
\text { saúde. }\end{array}$ & $\begin{array}{l}\text { Há necessidade de um esforço } \\
\text { combinado por parte dos } \\
\text { atores envolvidos neste } \\
\text { processo (aluno, tutor, } \\
\text { Academia, gerentes e usuários) } \\
\text { para a construção de espaços } \\
\text { e/ou instrumentos de discussão } \\
\text { como parte desta prática. }\end{array}$ \\
\hline $\begin{array}{l}\text { 11. Avaliação da } \\
\text { atenção em diabetes } \\
\text { mellitus em uma } \\
\text { unidade básica } \\
\text { distrital de saúde. } \\
\text { (2011) }\end{array}$ & $\begin{array}{c}\text { Avaliar os } \\
\text { componentes estrutura } \\
\text { e processo na atenção } \\
\text { ao usuário com } \\
\text { Diabetes Mellitus em } \\
\text { uma Unidade Básica }\end{array}$ & $\begin{array}{l}\text { Estudo quantitativo } \\
\text { transversal, onde foram } \\
\text { analisados } 138 \\
\text { prontuários de usuários } \\
\text { com Diabetes Mellitus. }\end{array}$ & $\begin{array}{l}\text { É importante que o enfermeiro } \\
\text { realize a intervenções } \\
\text { relacionadas ao autocuidado } \\
\text { aos usuários com } \\
\text { comprometimento visual, tais } \\
\text { como aplicação de insulina, } \\
\text { cuidado com os pés e } \\
\text { verificação do peso corporal. }\end{array}$ \\
\hline $\begin{array}{l}\text { 12. Competência do } \\
\text { enfermeiro na } \\
\text { atenção básica: em } \\
\text { foco a humanização } \\
\text { do processo de } \\
\text { trabalho (2012) }\end{array}$ & $\begin{array}{c}\text { Discutir as } \\
\text { competências que vêm } \\
\text { sendo ensinadas no } \\
\text { curso de graduação em } \\
\text { enfermagem. }\end{array}$ & $\begin{array}{l}\text { Pesquisa qualitativa, } \\
\text { realizada junto a docentes } \\
\text { e alunos da Escola de } \\
\text { Enfermagem da } \\
\text { Universidade de São } \\
\text { Paulo. }\end{array}$ & $\begin{array}{l}\text { Concluiu-se que existe uma } \\
\text { intencionalidade em se } \\
\text { direcionar a formação } \\
\text { profissional em enfermagem } \\
\text { para o fortalecimento da } \\
\text { Atenção Básica e da } \\
\text { humanização do cuidado. }\end{array}$ \\
\hline
\end{tabular}

A análise dos resultados desse estudo permitiu identificar 21 competências de enfermagem no âmbito da Atenção Básica descritas no Quadro 3.

Os resultados mostraram que existe um consenso em relação ao fato de que o enfermeiro tem perfil generalista, pois além de poder ter atribuições de coordenação, o enfermeiro deve agregar as atividades de assistência, gerir as atividades preventivas de promoção à saúde e funções administrativas, exercendo assim múltiplas funções.

Uma das principais competências do enfermeiro na Atenção Básica é a Consulta de Enfermagem, a qual tem o objetivo de prestar assistência sistematizada de enfermagem, identificando os problemas de saúde-doença, executando e avaliando cuidados que contribuam para a promoção, proteção, recuperação e reabilitação da saúde, com base no histórico de enfermagem ao exame físico, diagnóstico de enfermagem, plano terapêutico ou prescrição de enfermagem e avaliação da consulta ${ }^{8}$, apropriando-se de ferramentas como os Diagnósticos de Enfermagem, que permitem a determinação dos reais e potenciais problemas de saúde da população, oportunizando ações de promoção da saúde, prevenção de agravos e, consequentemente, a maximização da qualidade da assistência de enfermagem ${ }^{9}$.

Nesse interim, vale destacar a triagem com classificação de risco na Estratégia de Saúde da 
Família (ESF), que é a forma de reorganização da APS incorporando como princípios as diretrizes do Sistema Único de Saúde (SUS), universalização, descentralização e integralidade do cuidado, para garantir a equidade no acesso, de forma a satisfazer as necessidades de todos os cidadãos e superar as desigualdades, também apresenta a necessidade de organização do seu acolhimento com a devida classificação ${ }^{10}$.

Quadro 3. Síntese das competências identificadas, implicação para a prática da enfermagem e os artigos que abordam cada competência.

\begin{tabular}{|c|c|c|}
\hline $\begin{array}{c}\text { COMPETÊNCIA/ } \\
\text { AÇÕES DE CUIDADO }\end{array}$ & IMPLICAÇÃO PARA A PRÁTICA DO CUIDADO & $\begin{array}{l}\text { ARTIGOS QUE } \\
\text { ABORDAM A } \\
\text { COMPETÊNCIA }\end{array}$ \\
\hline $\begin{array}{l}\text { 1. Ações de } \\
\text { promoção, proteção } \\
\text { e restauração da } \\
\text { Saúde. }\end{array}$ & $\begin{array}{l}\text { Essas ações possibilitam o enfermeiro promover atividades } \\
\text { individuais e coletivas, realizadas e acompanhadas por equipes } \\
\text { multiprofissionais, atuando na promoção da saúde, à prevenção de } \\
\text { agravos, ao diagnóstico, à reabilitação e à manutenção da saúde. }\end{array}$ & 8 e 11 \\
\hline $\begin{array}{l}\text { 2. Acolhimento com } \\
\text { classificação de Risco }\end{array}$ & $\begin{array}{l}\text { Permite ao enfermeiro operar os processos de trabalho em saúde, } \\
\text { de forma a atender todos que procuram a Unidade Básica para } \\
\text { cuidados de saúde, oferecendo atendimento com resolutividade e } \\
\text { responsabilidade. }\end{array}$ & 12 \\
\hline $\begin{array}{l}\text { 3. Assistência } \\
\text { Humanizada }\end{array}$ & $\begin{array}{l}\text { O cuidado humanizado propicia uma melhor relação enfermeiro- } \\
\text { paciente, facilitando o processo de cuidar, fortalecendo a confiança } \\
\text { e o respeito profissional. }\end{array}$ & 8,9 e 12 \\
\hline $\begin{array}{l}\text { 4. Assistência ao Pré- } \\
\text { Natal de baixo risco }\end{array}$ & $\begin{array}{l}\text { Assistência de promoção e manutenção do bem-estar físico e } \\
\text { emocional ao longo do processo da gestação, parto e nascimento, } \\
\text { oferecendo informações e orientações sobre a evolução da gestação } \\
\text { e do trabalho de parto, desempenhando um papel importante na } \\
\text { redução de intercorrências obstétricas e da mortalidade materna. }\end{array}$ & 7 e 9 \\
\hline $\begin{array}{l}\text { 5. Atenção à Saúde } \\
\text { do Hipertenso e } \\
\text { diabético }\end{array}$ & $\begin{array}{l}\text { Permite vincular os indivíduos acometidos por estas condições } \\
\text { crônicas à unidade de saúde, garantindo-lhes acompanhamento e } \\
\text { tratamento sistemático, mediante ações promoção e proteção da } \\
\text { saúde, como forma de identificar lesões em órgãos-alvo e/ou } \\
\text { complicações crônicas e efetuar tratamento adequado para a HAS e } \\
\text { o DM. }\end{array}$ & 11 \\
\hline $\begin{array}{l}\text { 6. Consulta de } \\
\text { Enfermagem }\end{array}$ & $\begin{array}{l}\text { A consulta de enfermagem permeia a prestação de uma assistência } \\
\text { sistematizada de enfermagem, identificando os problemas de } \\
\text { saúde-doença, executando e avaliando cuidados que contribuem } \\
\text { para a promoção, proteção, recuperação e reabilitação da saúde. }\end{array}$ & 2,9 e 12 \\
\hline $\begin{array}{l}\text { 7. Cuidados } \\
\text { Paliativos }\end{array}$ & $\begin{array}{l}\text { Possibilita a melhoria da qualidade de vida do paciente e de seus } \\
\text { familiares, em face de uma doença que põe em risco a continuidade } \\
\text { da vida, mediante apoio biopsicossocial e espiritual. }\end{array}$ & 4 e 8 \\
\hline $\begin{array}{l}\text { 8. Diagnósticos de } \\
\text { Enfermagem }\end{array}$ & $\begin{array}{l}\text { Permite a habilidade de raciocínio e julgamento clínico do cuidado } \\
\text { em saúde, pois permite a identificação de problemas de saúde dos } \\
\text { sujeitos, norteando o processo decisório e, consequentemente, } \\
\text { influenciando o plano de intervenções. }\end{array}$ & 2 \\
\hline $\begin{array}{l}\text { 9. Educação } \\
\text { Permanente em } \\
\text { Saúde }\end{array}$ & $\begin{array}{l}\text { O desenvolvimento de grupos educativos pelo enfermeiro se } \\
\text { constitui como um espaço de interação e discussão coletiva entre } \\
\text { equipe e comunidade, com transmissão de informação, por meio de } \\
\text { atividades pedagógicas, fortalecendo a integração e discussão } \\
\text { coletiva. }\end{array}$ & 1,9 e 12 \\
\hline $\begin{array}{l}\text { 10. Encaminha- } \\
\text { mento para serviço } \\
\text { especializado }\end{array}$ & $\begin{array}{l}\text { Os protocolos de encaminhamento são uma ferramenta de gestão e } \\
\text { de cuidado, propiciando o cuidado continuado para consultas } \\
\text { médicas especializadas e procedimentos diagnósticos e terapêuticos } \\
\text { aos pacientes com maior risco, necessidade e/ou indicação clínica } \\
\text { especializada. }\end{array}$ & 4 e 11 \\
\hline $\begin{array}{l}\text { 11. Facilitador do } \\
\text { Autocuidado }\end{array}$ & $\begin{array}{l}\text { A atuação do enfermeiro, no que diz respeito à promoção do } \\
\text { autocuidado, propicia aos usuários o aprendizado em relação à sua } \\
\text { saúde, de modo a prevenir doenças ou cuidar da própria patologia, } \\
\text { bem como se tornam multiplicadores de saberes saudáveis. }\end{array}$ & 1 e 9 \\
\hline
\end{tabular}

Continua... 
continuação...

\begin{tabular}{|c|c|c|}
\hline $\begin{array}{l}\text { 12. Gestão da } \\
\text { Unidade de Saúde }\end{array}$ & $\begin{array}{l}\text { O gerenciamento da Unidade de Saúde e dos recursos humanos é uma } \\
\text { competência importante para administrar o trabalho da equipe, assim } \\
\text { como a competência interpessoal que auxilia o enfermeiro gerente no } \\
\text { enfrentamento de desafios em seu cotidiano, promovendo o } \\
\text { funcionamento aquedado da Unidade e dos atendimentos de saúde para } \\
\text { a população adscrita ao território. }\end{array}$ & 12 \\
\hline $\begin{array}{l}\text { 13. Habilidade com } \\
\text { informática e } \\
\text { computação }\end{array}$ & $\begin{array}{l}\text { Permite ao enfermeiro a possibilidade de gerenciamento de dados clínicos } \\
\text { e administrativos que podem ser registrados, armazenados, } \\
\text { compartilhados e acessados de forma eficiente e precisa de forma online, } \\
\text { uma vez que muitos processos básicos estão sendo "informatizados", } \\
\text { como o prontuário eletrônico, facilitando o acesso universal as } \\
\text { informações de saúde do paciente em qualquer unidade de saúde. }\end{array}$ & 3 \\
\hline $\begin{array}{l}\text { 14. Planejamento } \\
\text { Familiar }\end{array}$ & $\begin{array}{l}\text { O planejamento familiar permite ao enfermeiro oferecer recursos para } \\
\text { auxiliar tanto a concepção quanto a anticoncepção, conforme a escolha e } \\
\text { a necessidade do usuário, de modo que não coloque em risco a vida ou a } \\
\text { saúde das pessoas que os utilizam, garantindo também aos usuários o } \\
\text { direito de escolha. }\end{array}$ & 12 \\
\hline $\begin{array}{l}\text { 15. Preceptoria de } \\
\text { Enfermagem }\end{array}$ & $\begin{array}{l}\text { A preceptoria de enfermagem é uma competência que vem se } \\
\text { fortalecendo em parceria com estágios de graduação e programas de } \\
\text { residência na área da saúde, onde incube ao enfermeiro ensinar o } \\
\text { trabalho em equipe, comunicação, gerência, resolução de problemas, } \\
\text { promoção da saúde, atenção à saúde, valores profissionais, promovendo } \\
\text { o desenvolvimento profissional de enfermeiros residentes e acadêmicos } \\
\text { para os cuidados de saúde da população. }\end{array}$ & $6,7,10$ \\
\hline 16. Puericultura & $\begin{array}{l}\text { Por meio dessa competência é possível oferecer os serviços de saúde } \\
\text { voltados à priorização das ações preventivas e garantir adequado } \\
\text { crescimento e desenvolvimento da criança, focado em ações básicas de } \\
\text { saúde integradas, capazes de responder a problemas comuns na infância, } \\
\text { tais como incentivo ao aleitamento materno, imunização, controle das } \\
\text { doenças diarreicas, acompanhamento do crescimento e desenvolvimento } \\
\text { e controle das infecções respiratórias agudas. }\end{array}$ & 5 \\
\hline $\begin{array}{l}\text { 17. Evolução de } \\
\text { Enfermagem }\end{array}$ & $\begin{array}{l}\text { Possibilita ao enfermeiro registrar dados relevantes relativos ao paciente } \\
\text { em questão e os cuidados de saúde, permitindo uma atenção continuada, } \\
\text { sendo também um instrumento de respaldo legal tanto para o paciente, } \\
\text { quanto para o profissional de enfermagem. }\end{array}$ & $\begin{array}{c}3,7,9 \\
11\end{array}$ \\
\hline $\begin{array}{l}\text { 18. Solicitação de } \\
\text { Exames de Rotina }\end{array}$ & $\begin{array}{l}\text { O enfermeiro pode solicitar exames de rotina e complementares no } \\
\text { exercício de suas atividades profissionais dentro de programas de saúde, } \\
\text { tais como: Saúde da Mulher e da Criança, Diabetes, Hipertensão, com } \\
\text { respaldo na legislação de enfermagem, oferecendo garantias e cuidado } \\
\text { continuado à saúde da população. }\end{array}$ & 9 e 11 \\
\hline $\begin{array}{l}\text { 19. Vigilância em } \\
\text { Saúde }\end{array}$ & $\begin{array}{l}\text { Permite ao enfermeiro intervir sobre os problemas de saúde da população } \\
\text { nas várias fases do processo saúde-doença com a ênfase em problemas } \\
\text { que requerem atenção e acompanhamento contínuos, com } \\
\text { operacionalização do conceito de risco, articulando ações promocionais, } \\
\text { preventivas e curativas à saúde, a atuação intersetorial sobre o território. }\end{array}$ & 8 e 12 \\
\hline 20. Visita Domiciliar & $\begin{array}{l}\text { A prática da visita domiciliária pelo profissional de enfermagem permite } \\
\text { uma maior aproximação com a realidade vivenciada pelo indivíduo ou } \\
\text { comunidade, desenvolvendo assim, estratégias que podem potencializar } \\
\text { os fatores de proteção tanto do paciente quanto de sua rede de apoio. }\end{array}$ & $\begin{array}{c}4,5,8,9 \\
12\end{array}$ \\
\hline 21. Visita Puerperal & $\begin{array}{l}\text { Essa competência contribui na diminuição de casos de morbidade e } \\
\text { mortalidade materna e neonatal, aumentam o vínculo com a puérpera e } \\
\text { contribui para um cuidado integral, holístico e continuado. }\end{array}$ & 5 \\
\hline
\end{tabular}

O enfermeiro pode desempenhar funções de gestores, devendo este, realizar reuniões com as equipes, planejamentos relacionados aos programas nacionais, planejamento e realização de ações de controle às doenças e condições crônicas, reuniões com a comunidade, avaliação de desempenho, e atividades de educação permanente. Dentre outras funções exercidas estão: serviços assistenciais, responsabilidade técnica da unidade, coordenação dos programas, alimentação de sistemas de informação e responsabilidade pela ouvidoria da saúde ${ }^{11}$.

Uma vez que, para que haja o gerenciamento adequado dos recursos humanos de enfermagem em uma unidade de alta complexidade, o enfermeiro necessita conhecer a formação profissional e a disposição de seus colaboradores e aliá-las ao nível de complexidade 
exigida pela clientela por meio da liderança e tomada de decisões. Além disso, o cuidado de qualidade ao paciente está atrelado também aos materiais e equipamentos disponíveis. Portanto, não basta uma gestão eficaz de pessoas, é preciso que o enfermeiro tenha competências para gerenciar também os recursos materiais, bem como os financeiros ${ }^{12}$.

Além disso, um fator imprescindível nas competências de trabalho do enfermeiro é o exercício da liderança. A liderança envolve compromisso, responsabilidade, empatia, habilidade para tomada de decisões, comunicação e gerenciamento de forma eficaz ${ }^{12}$.

Nessa perspectiva, a tomada de decisão também é destacada como uma competência profissional necessária, por permear o processo de trabalho do enfermeiro e pode ser definida como complexa função em que é preciso optar entre uma série de alternativas, em especial em situações nas quais há certo grau de incerteza a respeito dos resultados da escolha. Dessa forma, os enfermeiros tomam decisões relacionadas à assistência de acordo com seu julgamento, sobre quais prioridades precisam intervir, necessitando para isso ter conhecimento e habilidades para avaliar e decidir sobre a melhor conduta ${ }^{12}$.

A comunicação adequada é uma competência relevante, pois além de ser o instrumento básico da assistência efetiva de Enfermagem, é através dela que se pode compreender o doente como um todo e identificar o significado que o problema tem para ele. O enfermeiro, conhecendo as técnicas de comunicação terapêuticas adequadas, tem mais um recurso a seu favor, dando um enfoque mais humanístico à comunicação e às relações interpessoais entre os usuários da $\mathrm{UBS}^{13}$.

Os artigos inferem ainda que o enfermeiro da atenção básica deve ser facilitador no desenvolvimento de competências e estimulação da promoção da saúde, para que os usuários sejam protagonistas do autocuidado, instituindo tecnologia leve de atos de cuidado, fundamentada em referências de enfermagem ${ }^{14}$. Além de desenvolver ações cuidativoeducacionais inovadoras e estar preparados para enfrentar problemas éticos, enfatizando a importância da educação ética durante o processo educacional antes e durante a prática profissional para melhorar o desenvolvimento da sensibilidade e competência ética para resolução de problemas ${ }^{15}$.

O acompanhamento ao pré-natal constituise num conjunto de procedimentos clínicos e educativos com o objetivo de vigiar a evolução da gravidez, bem como, orientar e esclarecer a mulher e sua família sobre a gestação, o parto e os cuidados com o recém-nascido. Busca ainda prevenir, detectar precocemente e tratar as intercorrências mais frequentes nesse período. ${ }^{16}$ O pré-natal se entende como o acompanhamento que a gestante recebe desde a concepção do feto até o início do trabalho de parto, durante este período a execução da educação em saúde pela equipe de enfermagem se faz de forma contínua através de informações acerca da gravidez, do feto, das modificações morfofisiológicas da gestante, bem como sobre trabalho de parto e cuidados pós-natal ${ }^{17}$.

O profissional enfermeiro precisa ter também competências técnicas e humanísticas na assistência ao recém-nascido. Na consulta de puericultura incumbe ao enfermeiro aferir o peso, altura, o desenvolvimento neuropsicomotor, vacinação, o estado nutricional, além de prestar orientações à mãe e a família, registrando toda a avaliação no cartão da criança, permitindo assim acompanhar o crescimento e desenvolvimento da criança ${ }^{18}$.

Também compete ao enfermeiro coordenar as ações dos agentes comunitários de saúde (ACS), supervisionar os auxiliares de enfermagem, além de vincular os indivíduos acometidos por condições crônicas, como hipertensão e diabetes, garantindo-lhes acompanhamento e tratamento sistemático, mediante ações promoção e proteção da saúde, como forma de identificar lesões em órgãos-alvo e/ou complicações crônicas e efetuar tratamento adequado $^{19}$.

Um dos recursos para prover tais cuidados integrais pode ser pelo desenvolvimento de grupos educativos, principalmente se esses se constituírem em espaços de interação e discussão coletiva entre equipe e comunidade. ${ }^{15}$

Destarte, o enfermeiro tem na atenção primária à saúde um amplo espaço de desenvolvimento para sua atuação profissional, seja por meio da consulta de enfermagem, no consultório ou no domicílio, como por meio de atividades de educação em saúde.

\section{Conclusão}

O contexto da Atenção Básica coloca o enfermeiro diante do desafio de desempenhar uma gama de atividades, visando à assistência holística e qualificada de enfermagem ao paciente, tornando-se essencial a aquisição de competências, buscando aperfeiçoar os conhecimentos, habilidades e atitudes a fim de aprimorar o seu processo de trabalho. 
Delineia-se que este estudo seja de grande relevância ao colaborar para que enfermeiros e organizações de saúde estejam atentos quanto às competências necessárias para atuar na Atenção Básica, uma vez que os resultados alcançados nesta revisão mostram que são decretadas múltiplas competências ao profissional enfermeiro. No entanto, algumas limitações podem ser citadas, como a busca de dados em apenas um idioma, já que provavelmente existam pesquisas publicadas em outros idiomas e em bases de indexação não incluídos neste estudo.

Não obstante, conclui-se que os resultados desta revisão são úteis para futuras pesquisas na área, para a prática e para a formação dos enfermeiros. Por meio da síntese dos resultados, permite-se a transferência de conhecimento aos enfermeiros, ao identificar suas funções da Atenção Básica, uma vez que poucos artigos evidenciaram as múltiplas competências de enfermagem, abordando em seu corpo textual apenas uma competência específica, evidenciando a necessidade de mais artigos com caráter mais amplo de abordagem.

\section{Referências}

1. BRASIL. Ministério da Saúde. Secretaria de Atenção à Saúde. Departamento de Atenção Básica. Política Nacional de Atenção Básica / Ministério da Saúde. Secretaria de Atenção à Saúde. 2012.

2. BRASIL. Ministério da Saúde. Secretaria de Atenção à Saúde. Departamento de Atenção Básica. Política nacional de atenção básica. Brasília: Ministério da Saúde; 2006.

3. Acioli $S$, Kebian LVA, Faria MGA, Ferraccioli P, Correa VAF. Práticas de cuidado: o papel do enfermeiro na atenção básica. Rev de enfermagem UERJ, Rio de Janeiro, 2014.

4. Facolli LA, Castro, DFA. Competência do enfermeiro na Atenção Básica: em foco a humanização do processo de trabalho. Rev 0 Mundo da Saúde, São Paulo. 2012.

5. Paiva KCM, Junior WJS. Competências profissionais de enfermeiros e sua gestão em um hospital particular. Rev Brasileira de enfermagem, Brasília, Dez. 2013.

6. Almost J, Wolff A, Mildon B, Price S, Godfrey C, Robinson S. Positive and negative behaviours in workplace relationships: a scoping review protocol. Rev BMJ Open. 2015.
7. Moura DCA, Greco RM, Leonel M. Saúde do Trabalhador - Produção Científica da Enfermagem na Primeira década do século XXI. Rev Enf-UFJF - Juiz de Fora, jul./dez. 2015.

8. Pereira RTA, Ferreira V. A consulta de enfermagem na Estratégia Saúde da Família. Barão de Maúa - Ribeirão Preto. Rev Uniara, v.17, n.1, julho, 2014.

9. Santos $\mathrm{KH}$, Marques D. Diagnósticos de Enfermagem na Atenção Básica: Contributos da Classificação Internacional para a Prática de Enfermagem. Rev. Soc. Bras. Enferm. Dezembro, 2015.

10. Roncato PAZB, Roxo CO, Benites, DF. Acolhimento com classificação de risco na estratégia de saúde da família. Rev da AMRIGS, Porto Alegre. 2012.

11. Carvalho BG, Peduzzi $M$, Nunes EFPA, Leite OS, Silva JAM. Gerência de unidade básica de saúde em municípios de diferentes portes: perfil e instrumentos gerenciais utilizados. Rev Esc Enferm USP. 2014.

12. Santos APA, Camelo SHH, Santos FC, Leal LA, Silva BR. Nurses in post-operative heart surgery: professional competencies and organization strategies. Rev ESC Enferm USP. 2016.

13. Haddad JGV, Amado JN, Machado EP, Zoboli ELC. A comunicação terapêutica na relação enfermeiro-usuário da atenção básica: um instrumento para a promoção da saúde e cidadania. Rev O Mundo da Saúde. São Paulo: 2011.

14. Barbosa, EMG. Educational technologies to encourage (self) care in postpartum women. Rev Bras Enferm.2016.

15. Goes TM, Polaro SHI, Golçalves LHT. Cultivo do bem viver das pessoas idosas e tecnologia cuidativo-educacional de enfermagem. Rev Enferm. Foco. 2016.

16. Barreto MS, Mathias TAF. Cuidado à gestante na atenção básica: Relato de atividades em estágio curricular. Rev Rene. 2013.

17. Carrara GLR, Oliveira JP. Atuação do enfermeiro na educação em saúde durante o pré-natal: uma revisão bibliográfica. Rev Fafibe Oline, nov. 2013.

18. Gomes ALM, Rocha CR, Tyrrell MAR. As competências técnicas dos enfermeiros na assistência ao recém-nascido. Rev Pesq.: cuid. fundam. Online. 2013.

19. Barros MR. Controle de hipertensos e diabéticos: Estratégias para atenção básica. TCC. Governandor Valadares/MG.2015. 
Endereço para Correspondência

Universidade Estadual Vale Do Acarajú - UVA

Av. da Universidade, 850 - Campus da Betânia, Sobral - CE

CEP.: $57030-680$

e-mail: girlane.albuquerque@yahoo.com.br

Recebido em 30/09/2017

Aprovado em 19/07/2018

Publicado em 12/09/2018 